\title{
The Makings of an Icon: Analysis of Photograph of Israeli Soldiers
}

\author{
Edna Barromi Perlman \\ University of Haifa, Haifa, Israel \\ Kibbutz College of Education, Technology and Arts, Tel Aviv, Israel
}

\begin{abstract}
This study analyses an iconic photograph of Israeli paratroopers, photographed in Jerusalem in 1967. It explores how visual and formal structural components in the image function in this photograph and how they contribute to the process of creating an icon. It explores the mechanisms that exist in visual icons and addresses the question of why some press photographs turn into iconic images while other do not, and if there is a connection between the visual structural elements in the images and the way they are perceived by the public. The study discusses how this visual logic correlates with other elements such as public opinion and myths.
\end{abstract}

Keywords: Photographs, icons, symbols, Israel, soldiers, myths, Zionism

\section{Introduction}

This paper analyses an iconic photograph of Israeli paratroopers at the Wailing Wall, photographed in 1967 by David Rubinger. ${ }^{1}$ The aim of this study is to understand how the structural, compositional and cultural elements in this selected photograph function and how they correlate with public opinion. The photograph serves as a case study analysis and presents an approach to understanding how meaning is constructed, in the process of observing photographs. The aim of this paper is to show how perception of photographs and making meaning is influenced by the construction of the image, the composition and the visual elements in the photograph.

Photographs in the media and the press can generate responses by the public that are contingent and in accord with public opinion. In the case of images of Israeli Defence Soldiers (IDF), responses are often strong and derive from an inherent notion that press images of the soldiers are real, that they relate to a record of history as it happened. This in itself correlates to a uniquely human process of making meaning, of recording and interpreting the world by creating images of it (Azaryahu \& Golan, 2012, p. 62). This study addresses the question of the relationship between the visual content and the public social and cultural iconic status of this image, which has maintained its status for close to fifty years. It explores how and in what way the compositional elements and internal order of the frame, the structure and construction of the photograph, contributed and affected its reading, beyond the historic and cultural events related to the time and place in which it was taken. The paper will relate to forms of Zionist propaganda photographs, common in Israel and

Edna Barromi Perlman, Ph.D., Researcher in the Institute for Research of the Kibbutz and the Cooperative Idea at the University of Haifa. Lecturer at the Kibbutz College of Education, Technology and Arts.

${ }^{1}$ David Rubinger, born 1924. Time-Life's primary photographer for the region, Rubinger covered all of Israel's wars. In 1997, Rubinger was awarded the Israel Prize, in communications-photography, becoming the first photographer to receive the award. 
their influence on the construction of Israeli photography and their effect on the case study photograph.

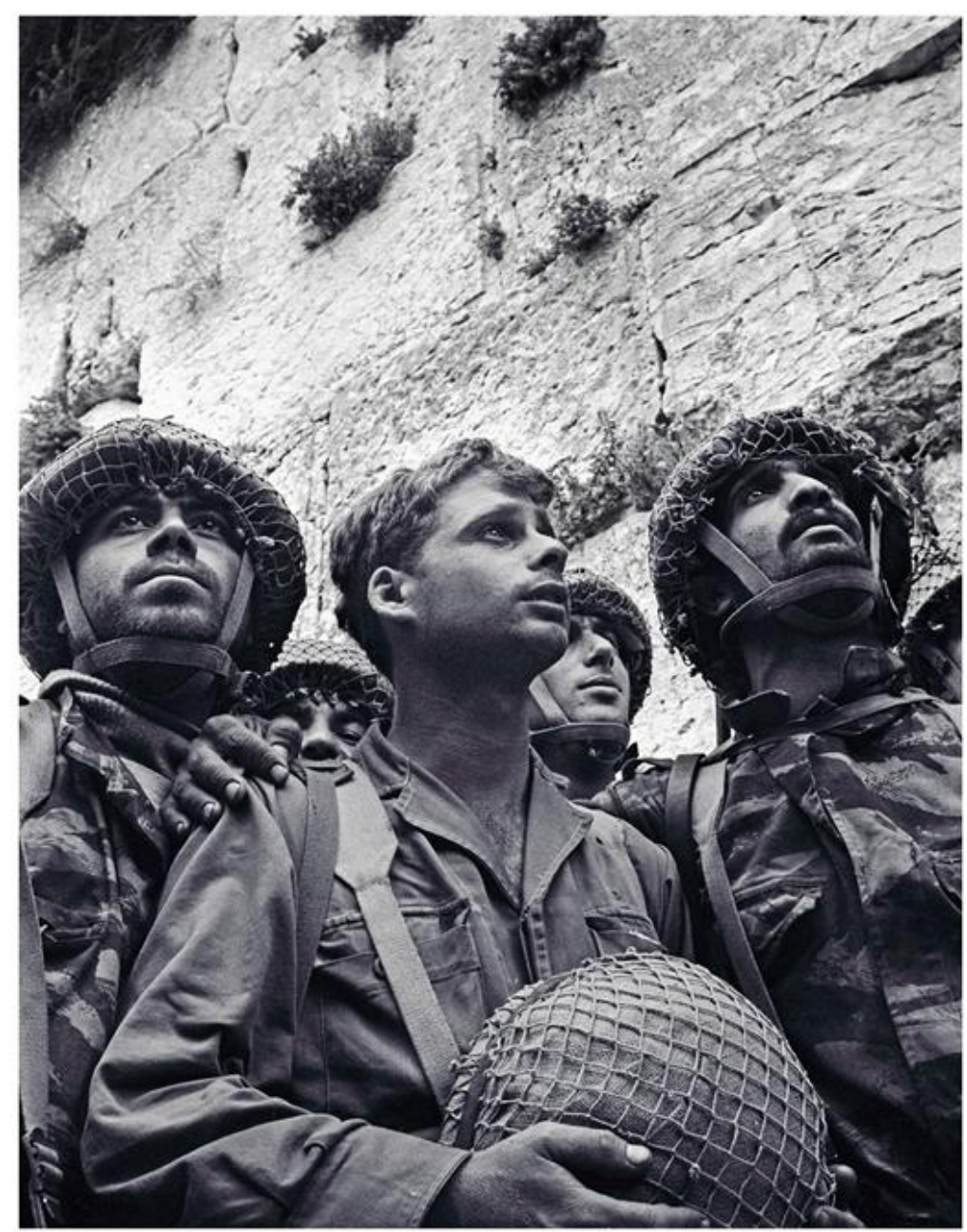

Figure 1. Paratroopers at the Wailing Wall in Jerusalem, 1967. Photograph by David Rubinger. Courtesy of Ye'di'ot Aha'ro'not Archive.

\section{Contextual Background}

Perez wrote that "contemporary Israeli photography as part of a culture is still in the process of forging its identity" (Perez, 2000, p. 120). Israeli documentary photography is concurrent with Israeli identity in the sense that shifting notions manifest themselves in shifting readings of visual icons. However, this selected photograph has stood out in Israeli society, in its symbolism, in how it is read and what it represents to the Israeli public. It represents a peak of national mainstream identity in Israeli history (Sela, 2008, p. 161). Sela (2008, p. 161) explains that it turned into an iconic figure in Israeli society, amongst others because of its vast distribution and use (Rubinger turned the negatives over to the government, who distributed it for 2IL each. It was then widely pirated). ${ }^{2}$ It mostly succeeded in describing the emotions of the Israeli public at the time, symbolizing the euphoria and feelings of empowerment and pride that many felt after the war, expressing the

\footnotetext{
${ }^{2}$ This was done as part of Rubinger's bargain with the Israeli Army that allowed him front-line access.
} 
superiority of Israeli soldiers (Sela, 2008, p. 168). From all the photographs of the Six Day War, according, this photograph was the one that remained in Israeli public consciousness for five decades, serving as an agent of a national unity (Sela, 2008, p. 170). Israeli Supreme Court Justice Misha'el Kheshin, declared in 2001 that the photo had "become the property of the entire nation". 3

Visual presentations of heroes, such as the Israeli paratroopers in the selected photograph, are susceptible to the dynamics of Israeli and international politics; representing a social and cultural consensus to certain audiences. At their peak, they can become engraved in local consciousness, turning into familiar symbols, until the point in which they cease to function as such and are replaced by others, or are subject to changing public opinion (Barromi Perlman, 2009). This is part of the process in which "historical and social memory [are] preserved, transformed, restricted and obliterated by photographs... " (Sekula, 2003, p. 444). This process is dynamic and exists so long as the information that flows towards the image creates the appropriate consensual interpretations, which enable accepted icons to function as such. This balance is based on the correlation between invested social interests and cultural contexts, which enable this relationship to exist.

\section{Visual Analysis}

The analysis utilised here is built on levels, as common in semiotics, the first one being what we can see in the photograph, recognizing the immediate signs which are apparent in the image (rifle, helmet, wall, etc.). The initial signs in the photograph, their location, shape, size and the degrees of proximity to the viewer and space between the people in the photograph are significant elements in the analysis. A soldier placed in the centre of the frame, or other soldiers photographed at a certain angle, might be perceived in different ways. Soldiers at the foreground or those at the back might be regarded differently. The second level of analysis relates to the parsing of the visual elements, identifying them and learning how they work, how they function behind the scenes, as well as their role in creating the signs and symbols.

This approach to visual analysis is one that focuses on formal components of the image, emphasizing the centrality of the sign system in the photograph, examining the structure of the photograph, the arrangement within the frame and the "dispositions, stances and gestures of its subject", according to Sekula (In Wells, 2004, p. 46). It analyses the proximity of the objects to the frame, to each other and their body language. The tools of analysis include investigation of elements such as proximity, haptics (nonverbal communication), body language, gestures and motions, eye contact, posture, use of background and various technical aspects such as use of angles and lens.

The selected photograph is presented as a case study, as a sample photograph from past historical events. Case study methodology enables the researcher to focus on a particularity and complexity of a single case, developing an understanding regarding its activity within certain circumstances, or as an instance of a wider phenomenon (Stake, 1995). This case study photograph, taken almost 50 years ago, enables the reader to adopt an appropriate academic distance from the historical events that took place during the war, in order to be able to consider it as a case study rather than a photograph representing current events in the Middle East. Furthermore, it is important to distance the method of analysis from a judgmental approach towards the events themselves. The purpose of this study is to understand how viewers make meaning of photographs and how icons can be contextualized as part of this process. The same analysis, employing the same methods, can be adopted on other

\footnotetext{
${ }^{3}$ Retrieved from http://en.wikipedia.org/wiki/David_Rubinger.
} 
iconic photographs, depicting historical events, employing the appropriate form of contextualization.

\section{The Role of Myths}

Much of the public in our present day postmodern society wants quick, unequivocal constructions and readings of events. Present day technology and circulation platforms such Facebook and Twitter create a range of artefacts, which are based on amateur photography, facilitated by domestic technology. Preferred images are those that are not time consuming but rather quick recording of images. Modern culture and media, including advanced media technology, have generated a public that prefers immediate images that function as clear identified visual texts, which point to a familiar and recognized reality. These images can be identified and read quickly, partly because they often contain clear, identifiable symbols, central compositional figures, all of which dominate the frame or the attention of the viewer. These images contain figures that are often focused, create eye contact with the viewer, can be appealing to the public and distinguished quickly.

The distribution of photographs plays a role in turning images into icons. Even the quick snapshots and the selfies can become visual icons, under the right circumstances. Cobley and Haeffner (2009, p. 126) describe a snapshot aesthetic. The circulation of certain snapshots in the media, such as in the case Abu Ghraib images in Iraq in 2003, gave them the status of artefacts of "citizen journalism" (Cobley \& Haeffner, 2009, p. 138). Citizen journalism is a form of a "digital amateur", which creates an erosion of the authority of the professional photographer. The addition of a story, a post on Facebook, a narrative, a blog, all play a role in the process of reading the photographs and constructing myths. Myths can contribute to the preservation of photographic icons even in amateur photographs; they encompass and shield them by creating accepted social contexts that enable icons to exist (Barromi Perlman, 2010). A myth can carry as much weight as the visual content of the image because myths function in consolidating uniform readings of the visual signs and prevent fluctuation in readings and interpretations of the image. Myths continue to exist so long as the information directed towards the image is conducive to the existence of a myth. The process of the deconstruction of the myths occurs when public criticism shatters the protective shield of uniform reading and deconstructs the iconic status of the image. This might mean that there exists a visual logic or possibly "fundamental characteristics of visual communication" (Messaris, 1997, p. vii). This serves as a logic that is the basis for the construction of visual signs that eventually turn into symbols, in the process of creation of iconic visual myths.

Notwithstanding, a myth can bestow the original signs and symbols with new meanings and readings, beyond the relationship between signified and signifier, which is a relationship that generates personal, individual readings of the signs in the image.

\section{Visual Myths in Israeli Society}

The state of Israel was established in 1948, in the middle of 20th century, a time in which visual propaganda was commonplace. The beginning of the statehood, in the late 19th century and early 20th century, was based on young pioneers from Eastern Europe, infused with ideology. This population was active in creating its identity based on local heroes and myths. Silver Brody writes, "Their work can be understood as planned image building in preparation for coming statehood" (Silver Brody, 1998, p. 75). Oren explains that nations "build national identity as a concept that feeds on both myths and the real life of individual and groups. Building a national identity is supported by cultural practices" (Oren \& Raz, 2008, p. 32). Photography was employed as one of those practices, resulting in the creation of professional documentary material by Zionist 
institution such as the Jewish National Fund (JNF), before the establishment of the state of Israel. Photographers were recruited to promote the idea of Zionism, the photographs succeeded in functioning as socializing agents, in developing local culture and heritage. The images proved to be a persuasive form of communication, generating emotional responses from Jews all around the world, successfully recruiting the Jewish Diasporas to support the pioneers.

Photographers, who came to Palestine before World War 2, were exposed to European and socialist genres of visual promotions of national ideologies. Many had been educated in Germany during the Weimar Republic. They had been exposed to different forms of new photojournalism and New Objectivity (Neue Sachlickeit). They were accustomed to European motifs in photographic style, to compositional perfection, order and organization, as well as avant-garde style. They brought with them a new vision and style, which had a major impact on Jewish photography in Palestine and Israel. The JNF commissioned photographs that were created with a common style of clarity, depicting reality in a way that provided an insight into the aspirations of the Zionist institutions. The use of imagery amongst the Zionist institutions was a form of propaganda that attempted to foster unity amongst the nation by means of visual imagery.

Their images were used to generate funds and promote Zionism. Zionist photographers, working in the service of the propaganda bureau of the JNF were recruited into the effort to sell an idea, to describe the fruits of Zionist labor and redemption of the land, according to the terminology common at the time (Barromi Perlman, 2007).

Figure 2 shows a woman pioneer, dressed in khaki clothes, ploughing fields. This photograph was taken at a low angle, which creates a dynamic dimension to the photograph. The low angle empowers the image as well as her height in relation to the viewer. She does not fill the frame, since it is filled with the machine she is employing, creating a balance with her presence and her actions. The machinery alludes to technology, which served the pioneers in their struggles. The photograph does not over-emphasize her feminine attributes; the clothes are unisex work clothes, which were common amongst women pioneers in kibbutzim (Helman, 2008).

The vision of the muscular Jew, female and male, the young pioneers, ploughing the fields, active in manual labour, worked hand in hand with the ethos and vision of the New Jew, one that JNF tried to promote for the purposes of propaganda (Barromi Perlman, 2007, p. 68). In the service of the JNF, the photographers concentrated on the creation of a new visual mythology. Their work was intended to encourage the formation of a nation and homogenize its identity for its people, a people that arrived in pre state Israel, from the four corners of the world; it attempted to create a unity for the displaced, disowned Jewish people. This created a platform for the infusion of Israeli society with images of glory, heroism and leadership, all-important in its struggle for nationhood and served as iconic representations that served the Jewish population in Israel and the Diaspora. This had an impact on styles of documentary photography in Israel for many years. These images generated a uniformity of reading amongst its viewers, although this dynamic has shown to be fluid and vulnerable, shifting according to varying public discourse and political agendas. 


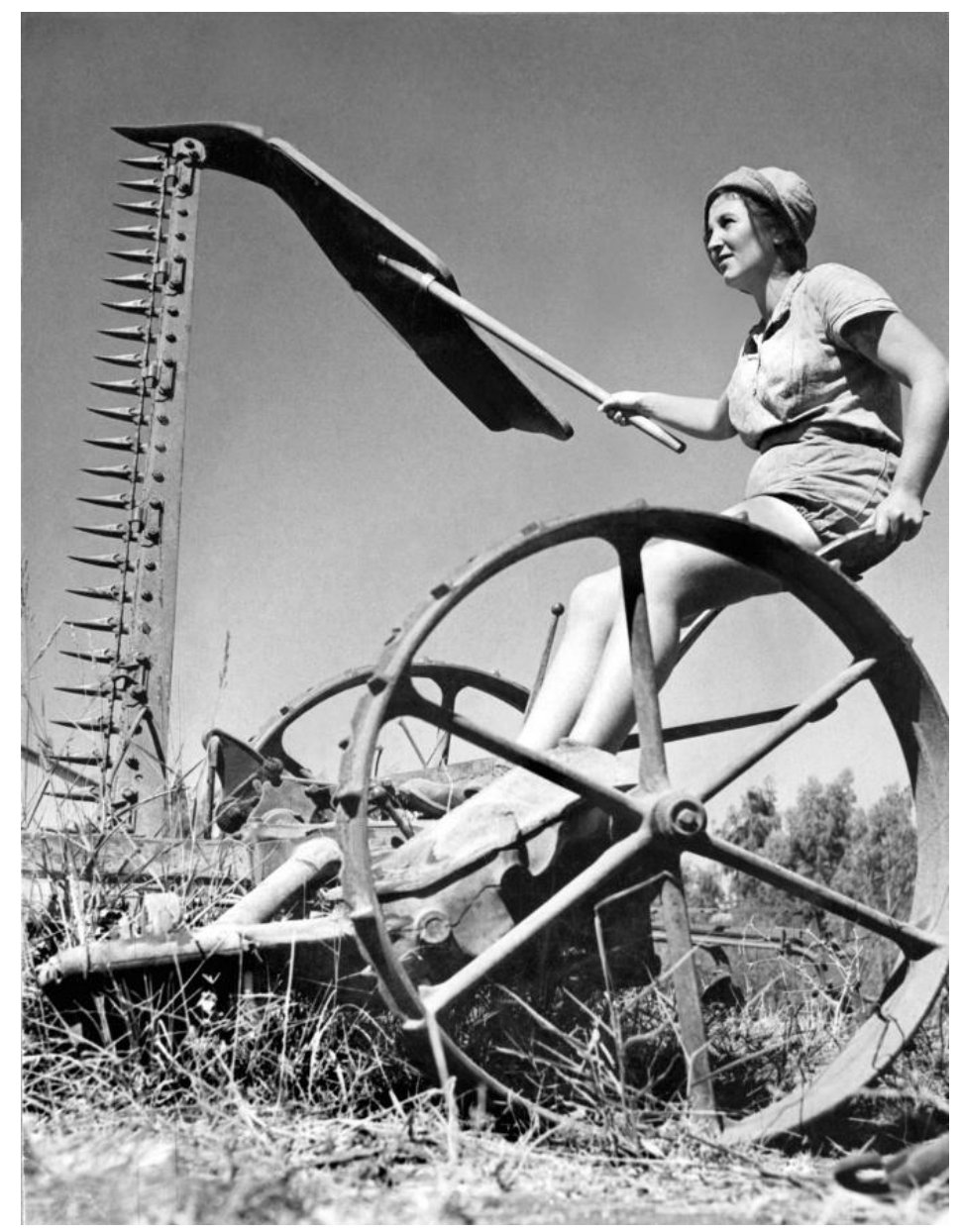

Figure 2. Women training to substitute mobilized men. Kibbutz Ein Hahoresh. Photograph by Zoltan Kluger, 1940. Courtesy of JNF archives.

\section{Analysis of Photograph of Paratroopers}

The photograph of three paratrooper soldiers was taken near the Wailing Wall (the last remnant of the original Jewish Temple), in the Old City in Jerusalem, at the end of the Six Day War, in June 1967. The Old City, which had been under Jordanian rule for nineteen years, was liberated by the Israeli army. These soldiers took part in the battle of the Jewish quarter in the old city and ended the battle at the Wailing Wall. The photograph was distributed in the Israeli press and became a popular visual representation of the victory of the war.

This photograph creates references to Israeli society's pioneering days, in which it dealt with developing visions of omnipotent heroes and visual representations of unity as well as messages of liberation and conquest. It reflected the mood and the feelings of the Israeli public, which was feeling victorious, after having been attacked by its neighbouring countries on all its borders. Klein-Halevi writes "To be and Israeli in the summer of 1967 was to be a hero. Everyone had a share in the victory" (Klein-Halevi, 2014, p. 118). The faces of the young soldiers, born around the time of the creation of the State of Israel in 1948, defending it triumphantly, struck a note in the hearts of the viewers. The photograph of the paratroopers at the Wailing Wall turned into an icon, recognized in Israeli society as a symbol of victory, a visual code of Israeli moral justification and of the military advantage of the Israeli army, at that time. The myths surrounding the photograph, combined with the 
historical events, carried the photograph into a realm of a cultural icon, beyond its function as a photograph.

Compositionally, the frame is constructed by a mass of soldiers at the bottom part, close to the viewer. They are gazing upwards to the horizon, which is emblematic of public hope. A small, pale background of the Wailing Wall is visible, which serves as a backdrop for the soldiers in the forefront. The Wailing Wall symbolizes the destruction of the Jewish Temple over two thousand years ago, and the positioning of the soldiers adjacent to the wall serves as a moving symbol of liberation, in the eyes of the Israelis. The soldiers are young and although they are portrayed as a mass of strength, the individual face of each one stands out and is discernible, so that they are recognized as individual human beings and as soldiers at the same time that reverberates an emotional tone to the viewers. They are holding apparent signs, such as military apparel, helmets, associated with the struggle of the soldiers. The soldier in the centre is white skinned with Ashkenazi (Eastern European) features, corresponding to the image of the fair haired, blue eyed New Jew, created by the JNF propaganda bureau. His external Ashkenazi features surpass the fact that he is the shortest soldier. The photograph symbolized the national ethos of unity, force and moral justification of the war according to the Zionist movement and the struggle of the Jewish people to return to the Promised Land. The focus and lighting are aimed at the soldier in the centre, but the viewer can discern the soldiers in the background who fill up the bottom half of the image. Their proximity can be read as a sign of force that generates a feeling of the power of the masses.

This image presents the process in which signs can turn into symbols if the political and social climate is conducive. Connor (1992) writes that "all images, photographic or otherwise, operate in a dense network of relationship with other forms of representation, textual, visual and psychic" (p. 97). The social climate of the time, which serves as the contextual framework for this photograph, alongside the need for heroic Jewish national symbols, encompassed the image of the paratroopers with a shield that served as a surrounding myth. In reality, this process was disconnected from the personal perception of the photographer, who was not happy with the result of the photograph and considered it a reject. Rubinger himself stated that he preferred another photograph from the same contact sheet, in which the Chief Rabbi was seen blowing the shofar (a horn blown on Jewish rituals). He was reluctant to hand that one over, and therefore provided this one to the papers as a default image ${ }^{4}$. In his own words: "I still don't think it's a great picture, but often iconic pictures are created by the media and what people read into them" (Ibid).

Notwithstanding Rubinger's claim that what people read into the photograph is that which turns it into an icon, a closer look at the photograph in Figure 3 reveals otherwise. The formal visual elements in the photograph of the upward gaze, the mass of soldiers and clear symbols all participate in constructing an icon, beyond the cultural and social myths linked to the glory of the Six Day War.

The photograph reflected mainstream trends in Israeli society at the time, created under the auspices of the Israeli Ministry of Defence and the Israeli Government Press Bureau. It represented to Israeli society a hegemony of the Jews over the Arabs in the Old City of Jerusalem, the conquest of the Jewish Quarter from the Jordanians. It supported the Israeli social order at the time of the war and the interests of offices of power. It enforced myths before the era of television in Israel, when radios were still a major source of information. The photograph served as an undisputable representation of the events, without the viewer's taking into consideration the facets of the medium itself.

\footnotetext{
4 2009, University of Haifa, live interview.
} 


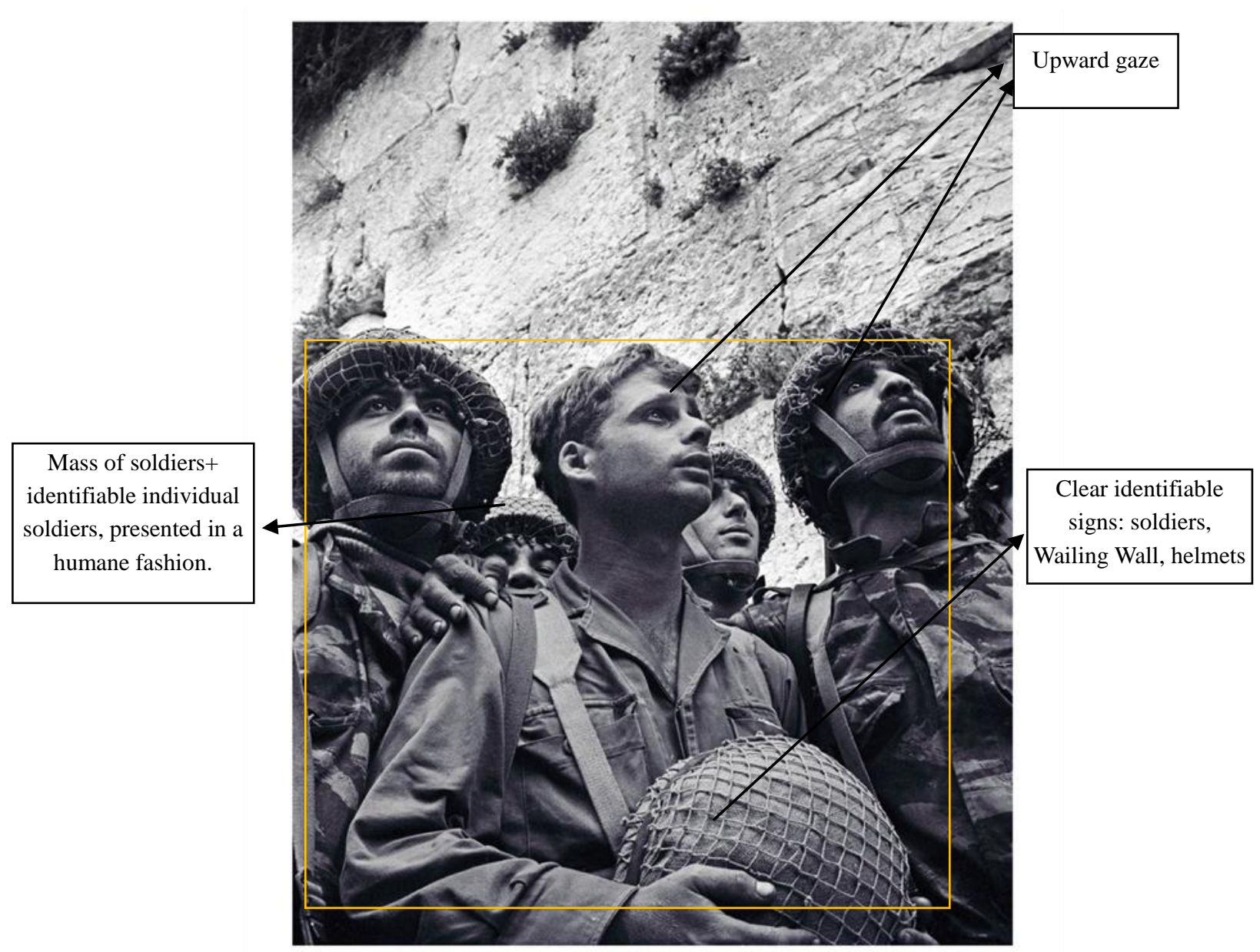

Figure 3. Paratroopers at the Wailing Wall in Jerusalem, 1967. Photograph by David Rubinger. Courtesy of Ye'di'ot Aha'ro'not Archive.

\section{Signs and Symbols in Photographs}

This photograph shows how a local cultural sign can turn into a symbol in relation to local and cultural codes and conventions. The helmet is not just a helmet but a helmet of a hero, and so forth. The signs in this photograph connect to meaningful and glorious moments in Israeli history, which in turn reflect back into the image. According to Goldberg (1991), historically, photographs

acquire symbolic overtones and larger frames of reference that endowed them with national or even worldwide significance. They concentrate the hopes and fears of millions and provide an instant and effortless connection to some deeply meaningful moment in history. (p. 135)

Photographs can be read differently in other cultures and periods. Any photograph of an armed IDF soldier can be a read as a sign of a man in uniform, or of a soldier, or an Israeli soldier, a sign of victory to some and a symbol of occupation and oppression to others. Clarke (1997) writes that the process of reading

...involves a series of problematic, ambiguous and often contradictory meanings and relationships between the reader and the image. The photograph achieves meaning through what has been called a "photographic discourse": A language of codes which involves its own grammar and syntax. It is, in its own way, as complex and as rich as any written language. (p. 27) 
Reading a photograph is “... to enter into a series of relationships which are 'hidden'.. by the illusory power of the image before our eyes" (Clarke, 1997, p. 29). Reading photographic icons does not demand intellectual or emotional investment, which is different from actually analysing photographs. It puts the viewer into a modus of reception and absorption, with no active buffering system, or active critical process. The necessary photographic discourse mentioned by Clarke, does not always take place. Tagg (1988) writes that the regular process of "encoding and decoding in photographs... is carried out by individuals who are themselves reciprocally constituted as the subjects of ideology in the unfolding historical process" (p. 188). Being a subject of ideology generates a process of reading icons that is characterized by passivity; the reader accepts the discourse and does not look for new or conflicting meanings. The reader does not create his own discourse or search for a decoding system since the social and ideological construction create uniform and consensual readings of the symbols in the photograph. This acceptance is part of the mechanism which enables the icon to exist in society. The symbols serve as a guide for the viewer, a roadmap that allows the viewer to orientate and eases the road to an immediate reading of the photograph.

Thus, the familiar symbols enable rapid and unambiguous readings of the imagery without which the viewer might get lost. Without the symbols, the viewer is required to make an effort to navigate in the picture, to focus, to find the point of connection and decode the signs individually. Without the apparatus of symbols, the viewer of the soldiers would have to struggle to construct his personal interpretations and create his own preferences. The viewer would be required to make an effort to navigate in the picture. In cases of ambiguity, the viewer might have to struggle to construct his individual interpretation and create his own preferences. This would entail looking for points of visual attraction, which pierce and penetrate, like the punctum, according to Barthes (1984), in which "a detail overwhelms the entirety of my reading; it is an intense mutation of my interest...This something has triggered me, has provoked a tiny shock..." (p. 49). Without the apparatus of symbols and cultural myths, viewers of a photograph of a soldier, would need to question each time whether an image of an armed soldier presents a defender of a just cause, a perpetrator or an offender.

\section{Conclusion}

Messaris (1997) writes about the power of photography to persuade. Persuasion can be achieved by means of proliferation of images, such as in advertising. This photograph is a documentary photograph, created by a professional photographer, with the purpose of documenting events as they happened, according to the codes of photography and documentation common in the 1960's. The result is a persuasive image of heroism, in the eyes of the Israeli public, one who views the image and identifies with the signs, symbols, stories and narratives related to the image.

The photograph has withheld shifting political discourse and controversy in the media. The original, un-manipulated black and white photograph, still maintains a stronghold on Israeli society. It is not only because it is a good photograph, it is also because this photograph reminds Israeli society of times in which it had moral justification for its actions, when there was strong international support for its political struggles.

The analysis of the photograph of the Israeli paratroopers presents an example of how visual signs serve as tools for reading photographs. The visual signs are convenient and functional, they function as a form of a roadmap that enables the viewer to orientate in the image and recognize where he is, geographically and historically. The lack of ambiguity amongst the viewers and the consensual reading paved the way to constructing a visual icon, in this case study photograph. This is conducive to current conventions of 
instantaneous and unambiguous readings of selfies and snapshots in the media. It is part of a mechanism of reading and making meaning of photographs, quickly. However, this mechanism is misleading. For example, the impressive choice of low angle and the distortion of the soldiers. All of which have become engraved in public memory as representations of heroism. The reason for this choice of low angle, as a form of manipulation, has become part of the myth surrounding the photograph. Rubinger recounted in various interviews how he "lay down to take the picture of the paratroopers because there was barely three metres between the Wailing Wall and the houses next to it" ${ }^{\text {" }}$. Current critics question the power hegemonies reflected in the image and why the low angle, chosen by the photographer, obliterates any mention of the surrounding Arab presence or buildings in the Wailing Wall area. The choice of angle and lens in this photograph were a result of the limitations rather than a stylistic choice. The choices create illusions and the visual result obliterates other contextual perceptions. Still, current public reading of this photograph in Israeli society, largely disregards the mechanisms of creating the photograph, the possible readings and interpretations of the image.

In conclusion, viewers are dependent on the mechanism, and although one feels that the perception, interpretation and making meaning is independent and individual, it is in fact the opposite. Viewers' responses are always a hybrid of social and contextual pressures and ideologies, of the motivation and intent of the photographer, as well as the extent of distribution of the photograph in the media.

\section{References}

Azaryahu, M., \& Golan, A. (2012). Photography, memory and ethnic cleansing: The fate of the Jewish quarter of Jerusalem, 1948-John Phillips' pictorial record. Israel Studies, 12(2), 62-76.

Barromi Perlman, E. (2007). Researching photographic representation of biological families in Kibbutzim in Israel between 1948-1967. Family Snaps on Kibbutz: Do they exist? (Ph.D. diss., University of Sussex).

Barromi Perlman, E. (2009). Icons of photo journalism: Signs and symbols. Proceedings from the Conference of the Department of Communication: The Battle over the Photograph: Photo Journalism in Israel, Between Military Icons and Social Icons. University of Haifa, Israel.

Barromi Perlman, E. (2010). Signs and symbols in Israeli photojournalism. Proceedings from the Third International Conference of Romanian Association of Semiotic Studies. Semiotics' Creativity: Unifying Diversities, Differences, Divides. Iasi, Romania.

Barthes, R. (1984). Camera Lucida: Reflections on photography. London: Flamingo Press.

Clarke, G. (1997). The photograph. UK: Oxford University Press.

Cobley, P., \& Haeffner, N. (2009). Digital cameras and domestic photography: Communication, agency and structure. Visual Communication, 8(2), 123-146.

Connor, S. (1992). Postmodernist culture: An introduction to theories of the contemporaries. Oxford: Blackwell Publishers.

Goldberg, V. (1991). The power of photography: How photographs changed our lives. New York: Abbeville Publishing Group.

Helman, A. (2008). Kibbutz dress in the 1950s: Utopian equality, anti-fashion, and change. Fashion Theory: The Journal of Dress, Body \& Culture, 12(3), 313-339.

Klein-Halevi, Y. (2014). Like dreamers: The story of the Israeli paratroopers who reunited Jerusalem and divided a nation. New York: Harper Collins.

Messaris, P. (1997). Visual persuasion: The role of images in advertising. Thousand Oaks, CA: Sage.

Oren, R. (2009). Collective memory in and age of changing media environments: The Israeli photographic heritage at the national institutions archives. The Romanian Journal of Journalism and Communication, 4, 31-46.

Oren, R., \& Raz, G. (2008). Zoltan Kluger, chief photographer, 1933-1958. Tel Aviv: Eretz Israel Museum.

Perez, N. (2000). Time frame: A century of photography in the land of Israel. Jerusalem: The Israel Museum.

Sekula, A. (2003). Reading an archive: Photography between labor and capital. In The Photography Reader (pp. 443-452). London: Routledge.

\footnotetext{
${ }^{5}$ Retrieved from http://www.theguardian.com/world/2007/may/06/israelandthepalestinians.features1.
} 
Sela, R. (2008). Changing images in national identity: From the photograph paratroopers at the wailing wall by David Rubinger to the photograph of the case bus number 300 by Alex Libak. Israel, 13, 161-180.

Silver-Brody, V. (1998). Documenters of the dream, pioneer Jewish photographers in the land of Israel, 1890-1933. Jerusalem: Magnes Press.

Stake, R. E. (1995). The art of case study research. London: Sage Publications.

Tagg, J. (1988). The burden of representation: Essays on photographs and histories. London: Macmillan Press.

Wells, L. (2004). Photography: A critical introduction (3rd ed.). New York: Routledge. 